\title{
Hidatidosis en el Valle del Mantaro, un problema de salud pública y quirúrgica, 2014
}

\author{
Hydatid disease in the Mantaro Valley, a public and \\ surgical health problem, 2014
}

\author{
Rigoberto Zuñiga Mera \\ Universidad Continental \\ jzuniga@continental.edu.pe
}

\section{RESUMEN}

Este trabajo tuvo como objetivos, determinar la incidencia de hidatidosis en la población del Valle del Mantaro; precisar cuál es la técnica adecuada, con menores complicaciones y más usada para el tratamiento de quistes hidatídicos tanto en pulmón como hepático. El método utilizado a estado basado en una evaluación estadística de Historias Clínicas de los principales hospitales del Ministerio de Salud de la ciudad de Huancayo como son: Hospital El Carmen, Hospital Daniel Alcides Carrión y centros de salud de la actividad privada. Los resultados indican que los casos mas frecuentes de hidatidosis encontrados fueron en varones y mujeres entre 10 a 19 años con valores de 20 y 16 respectivamente; la procedencia de los pacientes alcanza el mayor porcentaje en las localidades de Huancayo, Jauja, Sapallanga y Chupaca en el Valle del Mantaro; la localización más frecuente de los quistes pulmonares es en el pulmón derecho bilateral e izquierdo, con un total de 85 casos que supera a los hepáticos que alcanzan a 51 ; la sintomatología encontrada en los quistes pulmonares, son la tos y la expectoración hemoptoica y alcanza la mayor frecuencia así como los asintomáticos; con respecto a los quistes hepáticos, la temporización abdominal, hallazgos por imágenes y dolor en el hipocondrio son los más frecuentes. En conclusión, los habitantes del Valle del Mantaro presentan una elevada infección por Equinococcus granulosus que causa el quiste hidatídico pulmonar, los porcentajes en comparación al quiste hidatídico hepático son similares a otras localidades.

Palabras clave: Hidatidosis, hidatidosis pulmonar, hidatidosis hepática, quistes.

\section{ABSTRACT}

The objective was to determine the hydatidosis incidence in the Mantaro Valley population; to specify the proper technique with fewer complications and more used for the hydatidosis cysts treatment in both lung and liver. The used method is based on a statistical evaluation of clinical histories from the Health Ministry main Huancayo hospitals as: "El Carmen" Hospital, "Daniel Alcides Carrión" Hospital and health centers in the private sector. The results indicate that the most frequent cases of hydatidosis were found in men and women between 10 to 19 years old with values of 20 and 16 respectively; patients provenance reach the highest percentage in Huancayo, Jauja, Sapallanga and Chupaca locations in the Mantaro Valley; the most frequent localization of pulmonary cysts is in the bilateral and left right lung, with a total of 85 cases which exceeds the liver ones that reach 51 ; the found symptoms in the lung cysts, are cough and hemoptysis phlegm, and reaches the highest frequency as the asymptomatic; regarding the hepatic cysts, abdominal timing, imaging findings and hypochondrium pain are the most common. In conclusion, Mantaro Valley people have a high infection by the Echinococcus granulosus which causes lung hydatid cyst, the percentage compared to the hepatic hydatid cyst are similar to other locations.

Keywords: Hydatidosis, pulmonary hydatidosis, hepatic hydatidosis.

Historial del artículo:

Recibido: 16 de enero de 2015. Aprobado: 3 de mayo de 2015. Disponible en línea: 30 de junio de 2015

1 Doctor en medicina humana. Decano de la Facultad de Ciencias de la Salud de la Universidad Continental. 


\section{INTRODUCCIÓN}

La Hidatidosis o equinococosis es una enfermedad clasificada dentro de las ciclozoonosis que se transmite naturalmente entre los animales $y$ el hombre. Se entiende por zoonosis a las enfermedades e infecciones donde existe una relación animal hombre, directamente o a través del medio ambiente, incluido portadores, reservorios y vectores. Aquellas zoonosis en la que el agente infeccioso debe pasar por más de una especie vertebrada (perro - oveja) pero por ningún huésped invertebrado a fin de consumar su ciclo evolutivo se denomina ciclozoonosis; este grupo pertenece la equinocosis. Esta enfermedad se presenta en dos formas, en la etapa larval (metacéstode), y en la adulta (tenia) del parásito (1). La significación clínica y económica está casi totalmente confiada a la infección con el metacéstode.

En Perú, en la sierra central en 1993 los datos indicaban que el $12 \%$ de los perros estaban parasitados con Echinococcues granulosus, así como el $28 \%$ de los ovinos, $50 \%$ de los bovinos y $2,8 \%$ de los cerdos eran portadores del matacéstode. En el mismo año en la sierra sur del país el $31 \%$ de los perros, 13 . $50 \%$ de los ovinos, $16-69 \%$ de los bovinos y el 9,1 $\%$ de los cerdos (2). El estudio de la presencia de Echinococcues granulosus en 300 canes procedentes del cono norte de Lima mostro una prevalencia de 0,3 $+0,006 \%$, indicando que la enfermedad se mantenía igual a los niveles hallados, 27 años antes en el área metropolitana de Lima (3). La sierra central de Perú, posee el $95 \%$ de los casos de hidatidosis del país, con infestación en cabras, ovinos, llamas y cerdos.

La hidatidosis, equinococosis y desimanación, están influidas por muchos factores (agrícolas, ganaderos, económicos, culturales, etc) especialmente por la convivencia con el ganado, fundamentalmente en regiones agrícolas - ganaderas.

\section{Localización más frecuente}

La hidatidosis humana prevalece en el hígado (50-60 $\%)$, le sigue en frecuencia el pulmón (20-30\%), las otras localizaciones son: peritoneo (3-5\%), Riñón (1,5$2 \%)$, sistema nervioso $(2 \%)$, huesos $(2 \%)$, corazón $(0,2$ $\%)$, piel y musculo (4\%). En el hígado puede ocupar cualquier lugar, pero la ubicación más frecuente es en el lóbulo derecho, y con mayor frecuencia lo hace en la parte posterior superior de este (segmentos hepáticos VII y VIII de la clasificación de Couinaud) (4).

La hidatidosis hepática estadísticamente es la localización mas frecuente; por constituir la ubicación más importante dentro del abdomen, por la magnitud de las complicaciones y por las dificultades terapéuticas. Generalmente son quistes únicos, los múltiples son adyacentes entre si, separados por tabiques por los cuales transcurren vasos y canalículos biliares. La asociación con quistes en otros órganos es relativamente frecuente. La ubicación mas frecuente en el lóbulo derecho y dentro de el en el segmento 6 y 7 .

\section{Manifestaciones clínicas en hidatidosis pulmonar}

La evolución del quiste hidatídico puede ser silenciosa por varios años. Durante la etapa de crecimiento silente o preclínico, su presencia pasa inadvertido por el paciente y por el medico, luego se exterioriza por síntomas y signos inherentes al órgano donde se aloja (5).

En el pulmón el quiste no complicado presenta síntomas como: dolor vago, tos, expectoración o disnea (6) y en el examen físico, se muestra signos de tumoración como: matidez, disminución del murmullo vesicular y soplo (7). Puede presentar sintomatología de insuficiencia respiratoria (5).

El pulmón de características elásticas, ofrece una escasa resistencia a su crecimiento, ello determina un argumento del tamaño proporcionalmente rápido llevado a la aparición de síntomas clínicos en gran porcentaje de los casos (8). En la mayoría, los síntomas comienzan cuando el quiste tiene de 5 a $6 \mathrm{~cm}$. de diámetro.

Los quistes pulmonares se suelen descubrir durante una exploración radiológica del tórax efectuada por otras razones (9).

La mayoría de los enfermos presentan un solo quiste y es mas frecuente en el lóbulo inferior del pulmón derecho. La hidatidosis pulmonar múltiple puede ser primitiva o secundaria (6). En el primer caso, lo es frecuentemente por vía venosa, y la secundaria por contaminación local o embolígena proveniente de otras localizaciones a distancia (5).

Según Ivanissevich y Rivas la sintomatología que manifiesta el paciente esta referida en general a cuatro síndromes cardinales:

- Síndrome tumoral.

- Aumento de la consistencia del tejido parasitario.

- Aumento del volumen del órgano.

- Disociación de órganos circundantes.

- Alteración de las paredes.

- Síndrome doloroso: Sin caracteres específicos.

- Síndrome de hipersensibilidad: con reacciones generales y locales inherentes a la acción del antígeno hidático.

- Síndrome regional: con alteraciones anatómicas local y perturbaciones funcionales (5). 


\section{Manifestaciones clínicas en hidatidosis hepática}

Esta enfermedad suele cursar durante muchos años en forma asintomática, en ocasiones el diagnostico de hidatidosis hepática es un hallazgo durante un estudio por imágenes por otra afección (4). La mayoría de las infecciones se adquieren durante la niñez, pero salvo que los quistes se localicen en órganos vitales, es posible que no aparezcan síntomas durante décadas (10).

La sintomatología aparece como: tumoración palpable e indolora, dolores hepáticos, a veces del tipo cólico biliar con irradiación al hombro derecho, sensación de peso en el hipocondrio derecho y en el epigastrio, intolerancia a los alimentos grasos que ocasiona sensación de distensión abdominal $y$, por ultimo urticaria, síntoma común a cualquier localización (11).

La sintomatología es muy variable dependiendo de la ubicación y tamaño del quiste. Se describen las siguientes formas sindrómicas:

- Síndrome tumoral: aumento de volumen del órgano afectado, compresión de órganos vecinos, masa palpable.

- Síndrome doloroso: destrucción del parénquima afectado.

- Síndrome de hipersensibilidad: prurito, urticaria, asma, shock, muerte (1).

En el examen clínico debe valorarse el estado general y el estado nutricional del paciente, los que a menudo se hallan afectados. La hepatomegalia se observa como manifestación de quistes localizados en los segmentos inferiores o quistes intrahepáticos.

La semiología de la base del hemitorax derecho puede llegar a dar signos en caso de una elevación diafragmática en quistes de la región superior del hígado y tendrá hallazgos manifiestos de las complicaciones toráxicas de la hidatidosis hepática.

\section{Medidas para prevenir la hidatidosis}

\section{Identificación de factores de riesgo}

- Contacto con perros, propios o de la vecindad

- Acceso de los perros al consumo de vísceras crudas procedentes, bien de la propia alimentación que le suministra el propietario, bien porque pueda tener acceso a través de cadáveres animales, despojos procedente del sacrificio de animales.

- Consumo de frutas y hortalizas frescas sin adecuado lavado previo.

- Decomisos de mataderos.

\section{Medidas de vigilancia y control}

- Desparasitación de los perros del entorno mediante la administración de praziquantel $150 \mathrm{mg} / 10 \mathrm{~kg}$ p.v) advirtiendo al propietario de la necesidad de proceder a la destrucción de las heces del animal durante las 72 horas siguientes a la desparasitación.

- Incorporación al programa de control de la hidatidosis de aquellos animales que se considera necesario, mediante comunicación con el servicio de Sanidad Ambiental.

\section{Educación sanitaria:}

Está dirigido a la población general y población infantil. Consideramos la "población general" por la posibilidad de contacto con perros infectados o productos alimenticios contaminados con huevos del parasito (frutas, verduras, etc.). La población infantil merece una atención especial por el mayor riesgo de contacto estrecho con perros a través de juegos, caricias, etc. Aumentando las posibilidades de transmisión.

Dentro de la población general se pueden distinguir dos grupos que, además de estar en mayor medida expuestos a los factores de riesgo determinantes de esta enfermedad, pueden contribuir a perpetuar el ciclo biológico de la hidatidosis. También se consideran dentro de la población a los ganaderos de ovino y caprino fundamentalmente. Así como a los propietarios de perros de alto riesgo, ganaderos de otras especies, cazadores, rehalas, profesionales del sector cárnico, etc. Estos grupos tienen en sus manos la responsabilidad de tomar las medidas oportunas para evitar la infección en animales y en personas.

\section{Diagnóstico por imágenes}

Radiografía de pulmón de frente y perfil: se considera como la técnica de elección para (figuras $N^{\circ} 1,2,3$ ):

- Diagnostico en pacientes sintomáticos.

- Control del tratamiento.

- Encuestas de población para detección de portadores no sintomáticos a la localización pulmonar (8).

Los problemas identificados en esta investigación han sido definidas como:

- ¿Cuál es la procedencia de los pacientes?.

- ¿̇Cuáles son las condiciones sociales, sanitarias y económicas de los camales y matarifes en el Valle del Mantaro?

- Conocer la edad y el genero de los pacientes infectados con hidatidosis pulmonar hepática.

- ¿Cual es la localización de los quistes pulmonares, hepáticos o de otros órganos? 
- ¿̇Cuál es el procedimiento quirúrgico más empleado para el tratamiento de la hidatidosis pulmonar $y / 0$ hepática, y que complicaciones surgieron?.

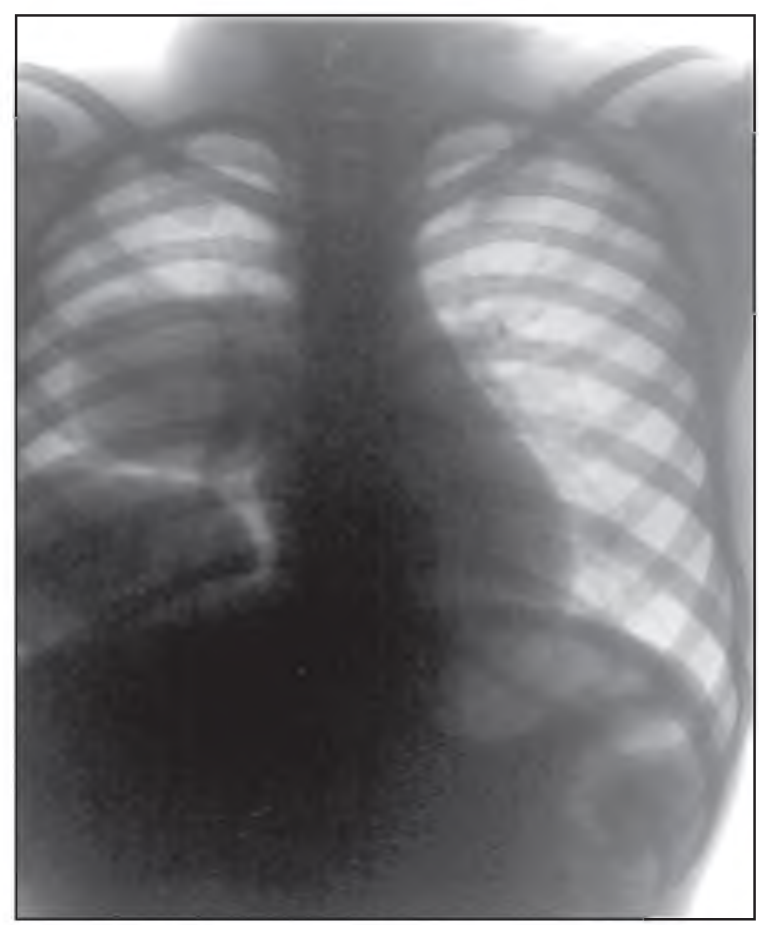

Figura $N^{0}$ 1: Radiografía de tórax que muestra varias imágenes quísticas.

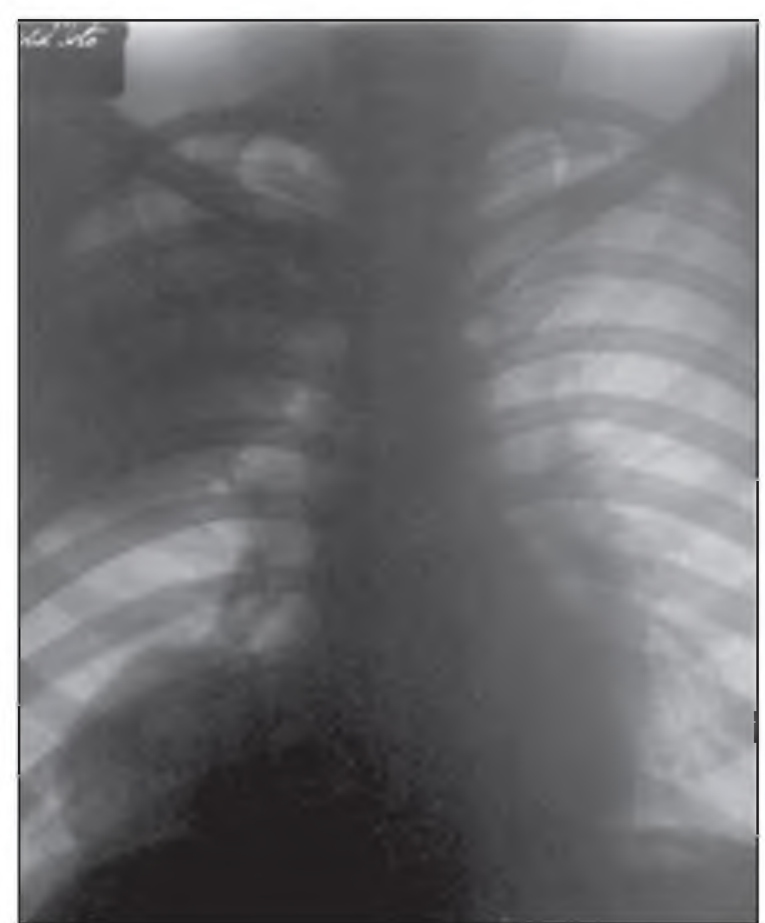

Figura $\mathrm{N}^{\circ}$ 2: Placa radiográfica con una quística pulmonar y la imagen del sol naciente de un quiste hepático.
Los objetivos logrados fueron:

- Determinar la incidencia de hidatidosis en la población del Valle del Mantaro.

- Precisar cual es la técnica adecuada, con menos complicaciones y mas usada para el tratamiento de quiste Hidatídico tanto en el pulmón como hepáticos.

\section{MATERIAL Y MÉTODOS}

Se evaluaron 158 historias clínicas de los hospitales: Daniel Alcides Carrión, El Carmen y de la práctica privada, 93 varones y 65 mujeres, de 10 a 50 años. Asimismo se investigó al ganado bovino y ovino de las localidades elegidas.

Dentro de los exámenes auxiliares los test de Casona y Weimberg dan posibilidad de $87 \%$ y $69 \%$ respectivamente; son más específicos la inmunelectroforesis, emaglutinacion indirecta; son de gran ayuda el diagnostico de la ultrasonografía, tomografía computarizada y anterografia.

El tratamiento quirúrgico estuvo orientado a esterilizar el quiste con solución salina hipertómica al $20 \%$ ó $30 \%$, remoción del contenido físico y el tratamiento de la cavidad residual, la misma que puede drenarse, rellenarse con epiplón, realizar capitonaje o resecarse.

La recopilación de datos se realizó mediante la observación documental y encuesta. El procedimiento y análisis de datos se efectuó mediante la estadística descriptiva.

Las variables definidas del presente estudio fueron: Sexo, edad, diagnostico, tratamiento y diagnostico por imágenes, residencia, localidad donde esta el camal o matarife de procedencia y aspectos sanitarios.

\section{RESULTADOS}

Uno de los más frecuentes problemas de salud que aquejan las poblaciones urbano marginales $y$ poblaciones rurales de nuestro país, son la zoonosis, tal como lo demuestra las elevadas consultas que atienden los Centros de Salud, tanto de las Postas Medicas de los lugares de residencia del poblador como los Centros Hospitalarios de las ciudades a los que acude en busca de ayuda médica, debido a las enfermedades transmitidas por animales.

Los casos mas frecuentes de hidatidosis encontrados fueron en varones y mujeres entre 10 a 19 años con valores de 20 y 16 respectivamente (tabla $N^{\circ} 1$ ).

La procedencia de los pacientes alcanza el mayor 
Tabla $\mathrm{N}^{\circ}$ 1: Edad y sexo.

\begin{tabular}{lcc}
\hline & \multicolumn{2}{c}{ Sexo } \\
\cline { 2 - 3 } Edad & Masculino & Femenino \\
\hline $0-9$ & 2 & 3 \\
$10-19$ & 20 & 16 \\
$20-29$ & 18 & 12 \\
$29-30$ & 16 & 14 \\
$39-40$ & 19 & 8 \\
$49-50$ & 12 & 8 \\
$59-60$ & 6 & 4 \\
$60-70$ & 0 & 0 \\
Total & 93 & 65 \\
\hline
\end{tabular}

Tabla $N^{\circ} 2$ : Procedencia.

\begin{tabular}{lc}
\hline & $N^{\circ}$ de casos \\
\hline Localidad & 83 \\
Juancayo & 12 \\
Sapallanga & 10 \\
Chupaca & 9 \\
Concepción & 7 \\
Huayucachi & 6 \\
Huancavelica & 6 \\
Tarma & 5 \\
Yauli & 4 \\
Lima (Yauyos) & 4 \\
Ayacucho & 4 \\
Pasco & 3 \\
Ancash & 2 \\
Lambayeque & 1 \\
Total & 158 \\
\hline
\end{tabular}

Tabla N³: Localización.

\begin{tabular}{lc}
\hline & No de casos \\
\hline Síntomas & 51 \\
Pulmonar & 28 \\
Derecho & 6 \\
Bilateral & 51 \\
lzquierdo & \\
Hepático & 2 \\
Otros & 6 \\
Pared toráxica & 5 \\
Pentoncal & 1 \\
Abdominal múltiple & 1 \\
Vesicular & 1 \\
Retropentoneal & 1 \\
Coxofamoral & 5 \\
Muslo & 158 \\
Pulmón - Hígado & Total
\end{tabular}

porcentaje en las localidades de Huancayo, Jauja, Sapallanga y Chupaca en el Valle del Mantaro (tabla $N^{\circ}$ 2). Los pacientes en la mayoría son estudiantes con residencia urbana y rural.

La localización más frecuente de los quistes pulmonares es en el pulmón derecho bilateral e izquierdo, con un total de 85 casos que supera a los hepáticos que alcanzan a 51 (tabla $\mathrm{N}^{\circ} 3$ ).

La sintomatología encontrada en los quistes pulmonares, son la tos y la expectoración hemoptoica y alcanza la mayor frecuencia así como los asintomáticos (tabla $\mathrm{N}^{\circ} 4$ ).

Con respecto a los quistes hepáticos, la temporización abdominal, hallazgos por imágenes y dolor en el hipocondrio son los más frecuentes (tabla $N^{\circ}$ 5).

Las intervenciones (tabla $\mathrm{N}^{\circ}$ 6) que se efectuaron a nuestros pacientes fueron los de localización pulmonar lobectomías para los quistes muy grandes y de resección segmentaria para los superficiales, en quistes pequeños optamos por el "parto del quiste" con ayuda del anestesiólogo, así como quistectonicos completos.

En los quistes hepáticos hicimos capitonaje, resección segmentaria y capitonaje transdiafragmatico.

Los habitantes del Valle del Mantaro presentan una elevada infección por Equinococcus granulosus que causa el quiste hidatídico pulmonar, los porcentajes en comparación al quiste hidatídico hepático son similares a otras localidades de la sierra central. Es así que Cerro de Pasco presenta un $71 \%$ de casos respecto al quiste hidatídico hepático, La Oroya presenta un $60 \%$, el Valle del Mantaro aparece con un $61 \%$ aproximadamente.

\section{Tratamiento de la hidatidosis}

\section{a) Tratamiento Médico}

En el tratamiento médico se administra Albendozal en dosis de $400 \mathrm{mg}$ dos veces al día durante doce semanas, es la más eficaz frente a los quistes hepáticos y pulmonares. La mejor forma de evaluar la respuesta al tratamiento consiste en estudios repetidos de los quistes mediante ecografías donde se presenta particular atención al tamaño y la consistencia. En los animales no se realiza ningún tratamiento, a pesar de que se han valorado diversos fármacos incluso en la especie humana (mebendazol, albendazol) y menos frecuentemente praziquantel. En los hospedadores definidos, es decir, principalmente praziquantel. En los hospedadores definitivos, es decir principalmente el perro, el tratamiento más eficaz es el praziquantel aunque también se han realizado experiencias con 
mebendazol, epsiprantel o niclosamida entre otros, no teniendo resultado halagador, existe un programa de erradicación de perros muy discutida.

\section{b) Tratamiento Quirúrgico:}

Indicaciones de la Cirugía:

En la actualidad, las técnicas quirúrgicas siguen siendo la herramienta terapéutica de elección para los casos de hidatidosis humana. Según recomendaciones de la Organización Mundial de la Salud (OMS) este tipo

Tabla $N^{\circ} 4:$ Sintomatología quiste pulmonar.

\begin{tabular}{lc}
\hline & \\
\hline Síntomas & $N^{\circ}$ de casos \\
\hline Tos & 46 \\
Expectoración & 18 \\
Hemoptoica & \\
Dolor Torácico & 6 \\
Hallazgos por imágenes & 5 \\
Asintomático & 10 \\
$\quad$ Total & $\mathbf{8 5}$ \\
\hline
\end{tabular}

Tabla N 5: Quiste Hepático.

\begin{tabular}{lc}
\hline & \\
\hline Síntomas & $N^{\circ}$ de casos \\
\hline Tumores abdominales & 21 \\
Hallazgos por imágenes & 12 \\
Dolor en H.D. & 10 \\
Asintomática & 6 \\
Dispepsia grasa & 2 \\
Total & 51 \\
\hline
\end{tabular}

Tabla $N^{\circ}$ 6: Intervenciones.

\begin{tabular}{lc}
\hline & \\
\hline Síntomas & $N^{\circ}$ de casos \\
\hline Pulmonar & 35 \\
Lobectomías & 22 \\
Resección segmentaria & 8 \\
$\quad$ Quistectomia & 6 \\
$\quad$ Parto del quiste & \\
Hepático & 40 \\
$\quad$ Capitonaje & 9 \\
Quistectomia - Drenaje & 2 \\
Resección Segmentaria & \\
Pulmonar - Capitonaje & 1 \\
Transdiafragmatica & \\
Quiste del muslo & 1 \\
Resección Quirúrgica & \\
Abdomen - Múltiple & \\
Resección - Drenaje & \\
Total & \\
\hline
\end{tabular}

de tratamiento es el recomendado en las siguientes situaciones (figuras $\mathrm{N}^{\circ} 3,4,5,6,7$ ):

- Quiste hepático de gran tamaño y con numerosas vesículas hijas.

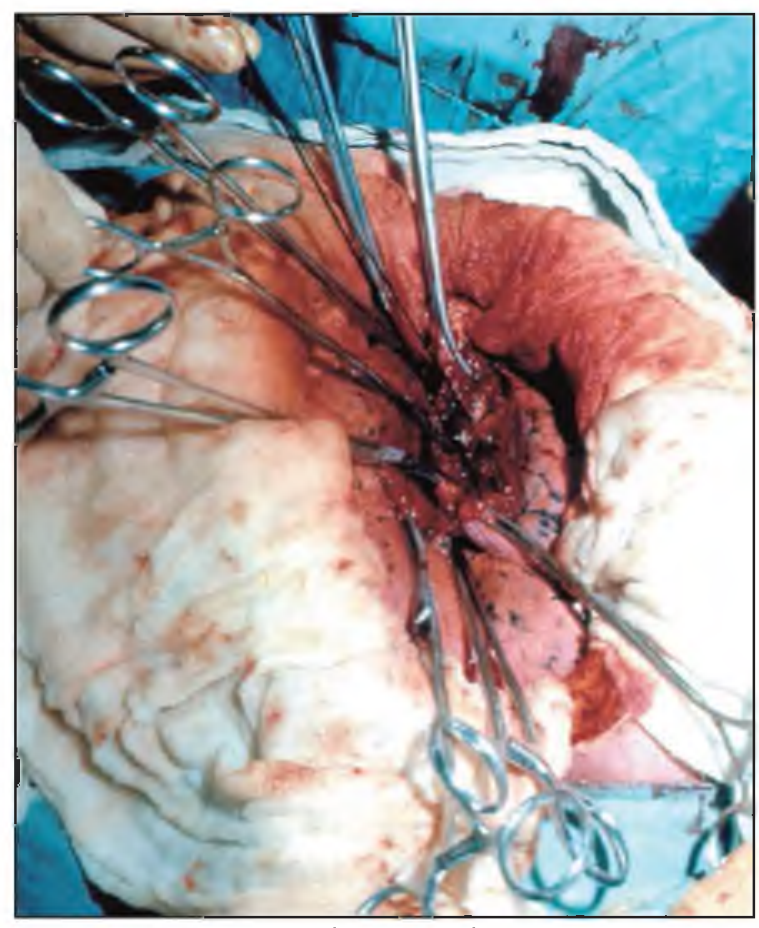

Figura $N^{\circ}$ 3: Extirpación de quiste pulmonar.

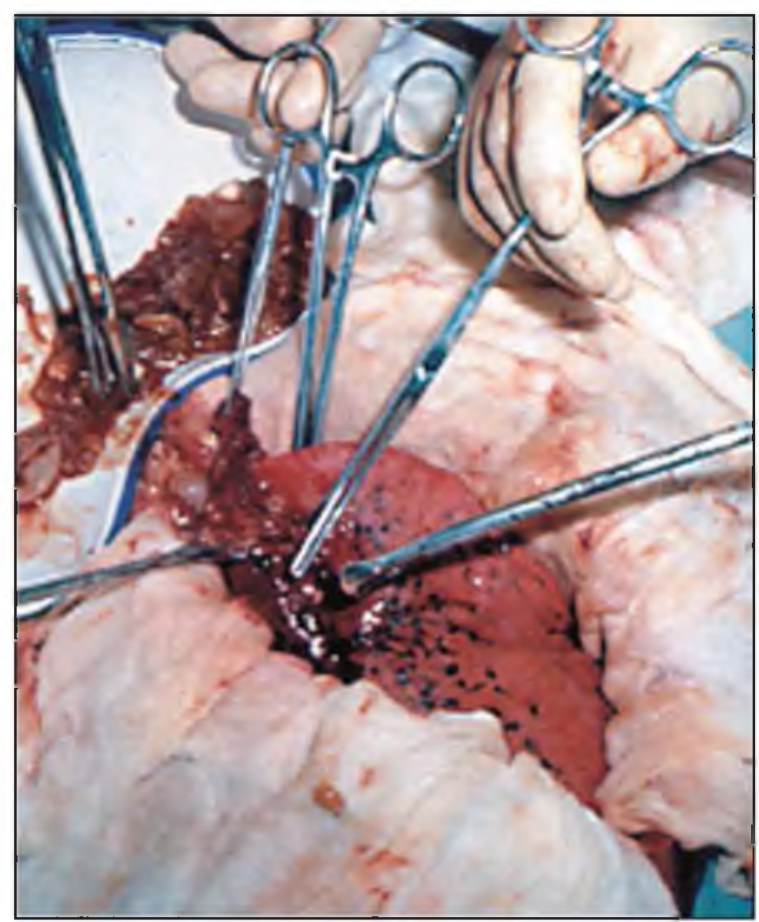

Figura $N^{\circ}$ 4: Extirpación de quistes hidatídicos con cuchara quirúrgica. 
- Quiste hepático único de localizaciones superiores y susceptibles de ruptura espontanea.

- Quiste infectados.

- Quistes que posean comunicación con la vía biliar.

- Quistes que ejerzan una presión importante, generado un efecto de masa ocupante sobre los órganos vecinos.

Las condiciones necesarias que debe cumplir todo tratamiento quirúrgico son: particular. Para encarar el tratamiento se deberán evaluar los siguientes factores:

- Edad y condición general del paciente

- Tamaño, localización, número, estado y evolución del quiste.

- Edad del parénquima circulante.

- Estado inmunológico.

- Equipo quirúrgico.

- Complejidad del control postoperatorio (UTI,

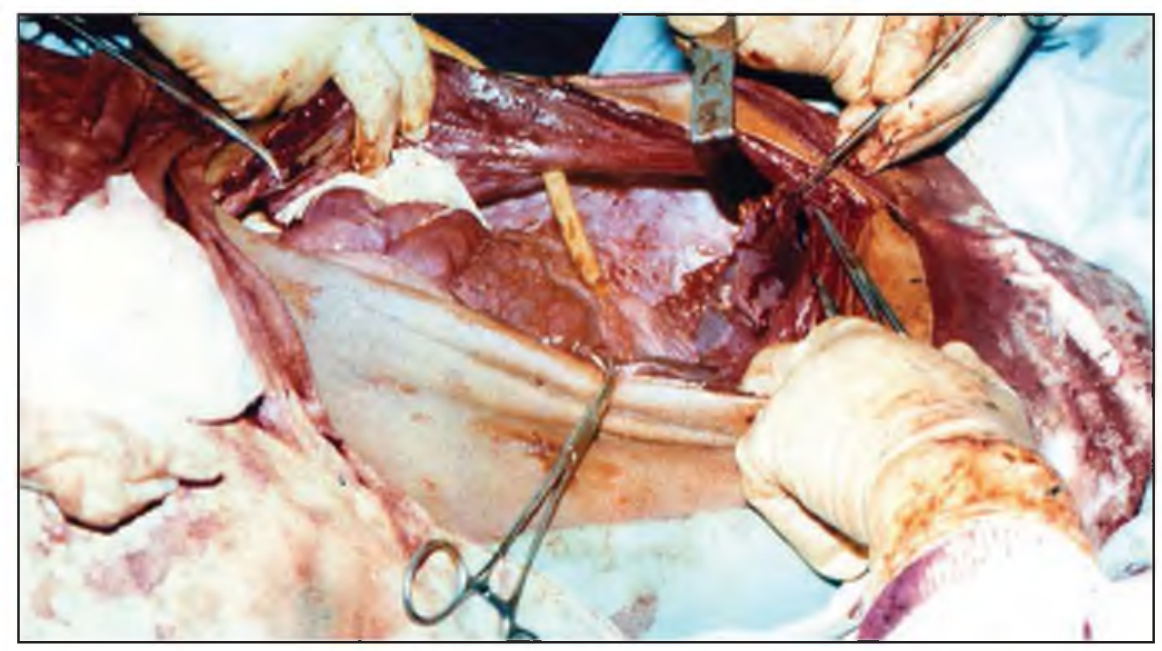

Figura $N^{\circ}$ 5: Cavidad abdominal después de la extirpación hidatídica.

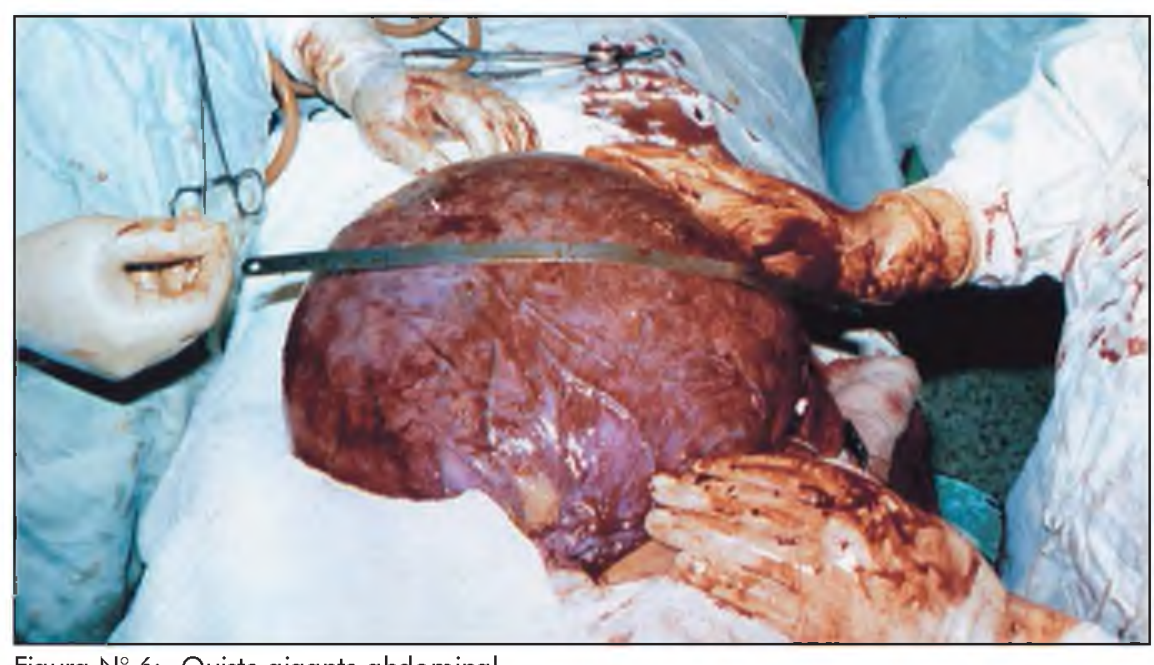

Figura $N^{\circ}$ 6: Quiste gigante abdominal.

- Evitar la contaminación.

- Impedir la persistencia de la cavidad residual.

- Impedir la supuración.

- Evitar la fistula biliar.

- Evitar la recidiva.

- Reducir la hemorragia intraoperatoria.

- Reinserción social precoz del paciente.

- Reducir el costo.

Es necesario adaptar la táctica a cada situación en
Guardia Activa, etc.)

Las metas de la terapia quirúrgica son:

- Erradicación del parásito.

- Prevención de la ruptura del quiste con el consecuente riesgo de diseminación de los elementos viables de Echinococcus granulosus.

- Extirpación de la cavidad residual con preservación del tejido del órgano afectado. 


\section{DISCUSIÓN}

La mayoría de autores indica una mayor localización en el hígado, lo que difiere de lo encontrado por nosotros (tabla $\mathrm{N}^{\circ} 3$ ).

En comparación a la aparición de casos en la sierra sur, en Juliaca también existe predominio de los quistes pulmonares sobre los hepáticos, en Arequipa aparecen casos alrededor del $60 \%$ de quistes hidatídicos pulmonares versus los hepáticos (12).

En Uruguay la incidencia acumulada de hidatidosis pulmonar se encuentra en porcentajes similares al de hidatidosis hepática, siendo la cifra de 3,0 por cien mil habitantes, mayor que en el Valle del Mantaro. Esto se explica por las extensas zonas ganaderas que posee Uruguay y por el número de ganados que alberga (13). temporización abdominal, hallazgos por imágenes y dolor en el hipocondrio son los más frecuentes, lo que también concuerda con los diversos autores.

Algunas conclusiones son:

- La incidencia de la hidatidosis pulmonar y hepática es alta en el Valle del Mantaro.

- En cuanto a los métodos de diagnostico, la radiografía pulmonar es un método muy confiable para los quistes pulmonares y la ecografía para los quistes hepáticos.

- La cirugía es el método racional para el tratamiento de la hidatidosis en el Valle del Mantaro, aplicando las técnicas quirúrgicas adecuadas.

- La población urbana, urbano marginal y rural del Valle del Mantaro tienen en su mayoría deficientes hábitos de higiene y desconocen medidas de prevención sanitaria para evitar la contaminación

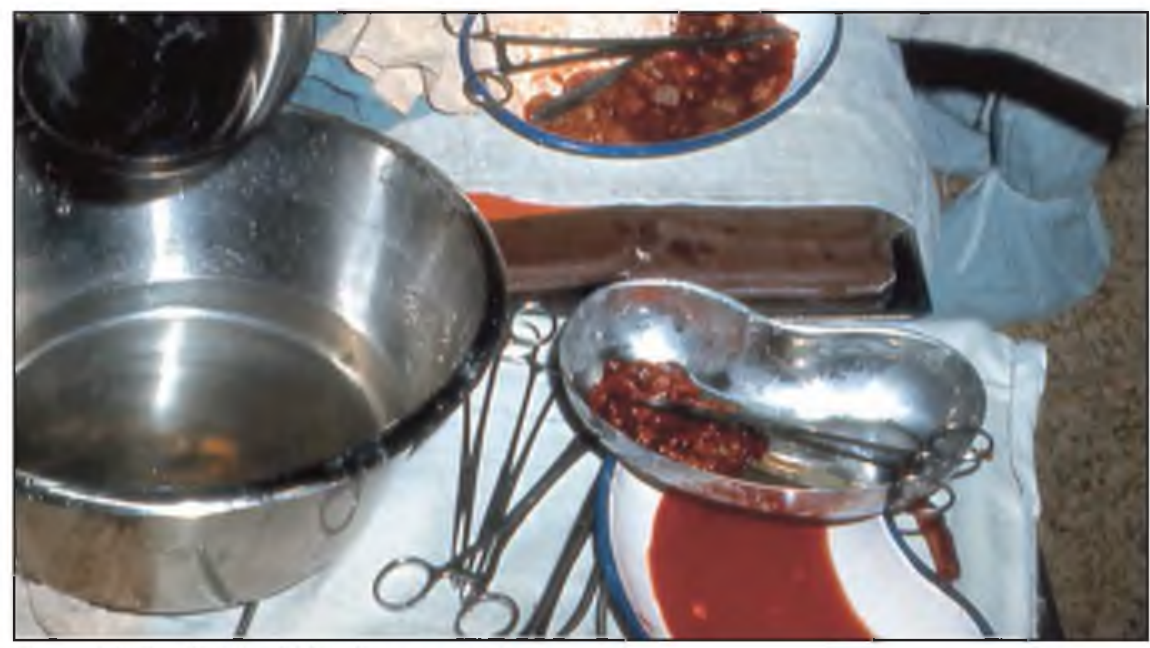

Figura $N^{\circ} 7$ : Quistes hidatídicos pequeños.

Comparando las cifras con otros países, en Chile la incidencia de hidatidosis fluctúa entre 6,5 y 11,4 por cien mil habitantes, siendo la hidatidosis pulmonar la de mayor porcentaje (50\% aproximadamente) (14), un poco por encima de la incidencia del Valle del Mantaro.

Argentina posee la frecuencia mas alta en Latinoamérica, siendo la provincia de Buenos Aires y Corrientes. En Rio Negro, Chubut, Neuquen y Tierra del Fuego, en el periodo entre 1984 - 1988 la tasa de incidencia fue de 41 por cada cien mil habitantes (15), muy por encima de la que sufrimos en esta parte del país.

La sintomatología encontrada en los quistes pulmonares, la tos y la expectoración hemoptoica alcanzan la mayor frecuencia así como los asintomáticos. Con respecto a los quistes hepáticos, la con el equinococos.

- La hidatidosis es un problema de salud pública relacionado con aspectos socio cultural y económico, por lo que se debe diseñar una estrategia que involucre al estado, universidades, municipios y la población en general con talleres de programas sanitarios para prevenir la difusión de la enfermedad.

\section{REFERENCIAS BIBLIOGRÁFICAS}

1. Vera MG, Venturelli F, Aliro Venturelli A. Hidatidosis humana. Cuad de Cirug. 2003; 17: 88-94.

2. Gonzales J. Equinococosis Canina en Huancayo 1996. Congreso Panamericano de Medicina de 
Altura - V Jornada de Patología Andina. Huancayo: Libro de Resúmenes; 2001.

3. Chuquisana J, Chávez VA, Casas AE. Determinación de Echinococcus granulosus en perros del Cono Norte de Lima. Rev. Inv. Vet. 2000; $11: 126-131$.

4. Feraina P, Oria A. Cirugía de Michans. 5 ed. Buenos Aires: El ateneo; 2003.

5. Gorodner J. Hidatidosis. En: Gorodner JO, Gorodner AM, de Enfermedades infecciosas. 2a ed. Rosario: Corpus; 2004.

6. Sapunar J. Hidatidosis. En Atias A, de: Parasitología médica. Chile: Publicaciones Técnicas Mediterráneas. 338-354.

7. Botero DR, Restrepo MI. Helmintiasis tisulares. En: Restrepo AM, Robledo J, Bedoya VIE, de: Enfermedades infecciosas. 5ㅁ ed. Medellín: Corporación para investigaciones biológicas; 1996.

8. Larrieu E, Del Carpio M, Gatti A, et al. Normas de diagnóstico y tratamiento de la Hidatidosis humana. Río negro: Secretaria de estado de salud; 2002.

9. Berkow R. El Manual Merk, $10^{\varrho}$ ed. Madrid; Harcout: 1999.

10. Merk HB. El Manual Merk: de diagnóstico y tratamiento. 10 ed. Madrid; Harcourt: 2001.

11. Atias A, Neghme A. Parasitología Clínica. $2^{\text {a }}$ ed. Santiago de Chile; Publicaciones Técnicas Mediterrá- neo Ltda: 1984.

12. Zela R. Incidencia de la hidatidosis humana y evaluación clínica - quirúrgica y complicaciones de pacientes tratados quirúrgicamente en el hospital Carlos Monge Mediano de la ciudad de Juliaca, Enero 1990 - Diciembre 1997. Arequipa; 1998.

13. Perdomo R, Parada R, Alvarez C, Cattivelli D, Geninazzi $H$, et al. Estudio epidemiológico de hidatidosis: Detección precoz en áreas de alto riesgo. Rev Med Uruguay. 1990; 6(1): 34-47.

14. Serra I, García V, Pizarro A, Luzoro A, Cavada $G$, et al. Un método universal para corregir la subnotificación en enfermedades transmisibles: incidencia real de la hidatidosis humana en Chile: 1985-1994. Rev Med Chil. 1999; 127(4): 485492.

15. Larrieu E, Frider B, Del Carpio M, Salvitti JC, Mercapide $C$, et al. Portadores asintomáticos de hidatidosis: epidemiologia diagnostico y tratamiento. Rev Panam de Salud Pública. 2000; 8(4): 250-256. 